For those of us in the second rank of GPs, who are, of course, the majority, vocational training can undoubtedly be of great importance in moulding attitudes and in developing clinical skills. Unfortunately it can be manipulated to serve undesirable objectives. That so many of these courses are in the hands of zealots more concerned with the power game than with the careful development of their own practices is a matter for deep concern. The danger is that some trainees will become conditioned to an attitude that places a higher value on group discussions and on committee decisions, on conformity to a norm established on high, than on personal commitment to the care of one's patients.

Indeed, perhaps the biggest problem facing us today is that young doctors tend to be shielded for too long from direct and continuing acceptance of clinical responsibility for their own patients in their own practice. This commitment must be the ultimate goal of all training, and to defer its realisation unduly is a fundamental mistake.

Speed limits, and tests for learner drivers, have to be set with the objective of making the worst drivers as safe as possible; one accepts that. But the analogy should not be applied strictly to training for general practice, or we shall destroy that individuality and sense of personal commitment which is at the core of our work.

The imposition of a rigid three-year package, culminating in the membership examination as the sole portal of entry to general practice, in a service under the control of a monopoly employer would be a disaster for our patients. Dr Brown's letter underlines the real threat that just such a process is now taking place.

Cyril Hart

Peterborough PE7 3RH

\section{The middle grade}

SIR,-Since surgeons and physicians have to have assistants but train more than one successor during their life time, the career structure must by necessity take the form of a pyramid. I have never understood how this basic fact can be ignored. It seems to be accepted by other professions. Not every major becomes a colonel or every teacher a headmaster. But in medicine today everyone who has put a foot on to the bottom rung of the ladder demands a guarantee of promotion to the top.

It has not always been so. When I worked for the London County Council before the war, I met competent men who preferred a 9-5 (or 10-4) job to the atmosphere of Harley Street and the medical school. I remember a physician who because of a mitral stenosis wanted a quiet life, and a surgeon who did a very adequate cholecystectomy or hernia repair but whose passion for bridge filled up all the spare time which he might have spent on reading or on attending meetings. It was accepted that they would not set the Thames on fire and that they had exchanged a fairly limited salary for a more peaceful existence. I believe also that there was no shortage of applicants for such a grade. I knew several SHMOs who were perfectly happy with their lot. But nothing was heard of them, since it was not they who organised protest meetings or wrote letters to the press. The grade may well attract a man who has difficulties with examinations or likes to get home to his children when he has finished his work.

A few months ago I listened to a BBC programme called "The Leader of the Orchestra." The duties of this man were described (rehearsals) and his position (spokesman for the orchestra and sometimes mediator between it and the conductor), and then finally the interviewer felt obliged to ask the awkward question: "How did they feel about not having reached the top?" The replies were much in line with my thinking. They were given by people to whom a quiet life of an orderly foundation had greater attraction than the hectic glamour of the star performer with its richer rewards but its nervous strain.

The value of such appointments to the hospital service has been amply described by Professor Norman Browse (15 September, p 682) and I need add nothing to that. I will be told that an assistant grade could easily be abused. But any relationship can be abused, and I am not particularly impressed by this charge because I have heard junior staff complain alternately that the chief "never lets them do anything" or that he never turns up and that they "do all the work." What I would admit is that it is the detractors who get the publicity nowadays, whether their subject is marriage, parents and children, or medical career structure, It was the detractors' sneer about cut-price consultants which led to the end of the SHMO grade, a grade of the greatest value to the hospital service and one which can give immense satisfaction for that very reason.

Sheffield

\section{E G Herzo}

\section{Medically qualified preclinical academics}

SIR,-A report on medical academic staff (14 July, p 146) mentions that the ViceChancellors and Principals Committee is examining the possibility of medically qualified preclinical staff being offered clinical appointments. I would like to point out that a concurrent clinical attachment should not be the prerequisite for a better income. Many such academics are primarily inclined towards basic research, and indeed contribute significantly to medical knowledge. The research output of these valuable workers will be hampered by this new responsibility, which would be regarded as a form of "moonlighting."

The award of an equitable remuneration should instead be based upon the simple and obvious fact that medically qualified preclinical academics play a vital role in the professional training of medical students. ${ }^{1}$ In view of the rapid scientific advances and increased curriculum loads nowadays, only such academics have the competence to rationalise, select, integrate, and teach effectively those basic principles which are relevant to professional requirements. We have only to recall our own preclinical experiences to realise that much of what was essential was invariably taught by medically qualified staff; their professionally orientated guidance not only facilitated learning and generated interest but also provided a sound and lasting foundation for the clinical subjects.

Commonwealth universities also have difficulty in recruiting medically qualified preclinical teachers because of poor salaries in comparison with clinical scales. The wellknown unsatisfactory effects of this deficiency need no elaboration. Only one Commonwealth university in the Far East, to my knowledge, laudably attempts to minimise the salary disparity by awarding a "medical allowance" to attract and retain medically qualified preclinical academics; but no clinical attachment is necessary.

Administrators often voice concern over the serious shortage of medically qualified preclinical teachers and yet, pathetically, lack the foresight to tackle the real root of the problem. Policies appear to be influenced by non-medically qualified key administrators who presumptuously decide the preclinical needs of the medical profession. An example of this is the grossly unsound opinion of the Department of Education and Science that a medical qualification is not needed.

We must unite in pressing for a satisfactory solution and make it clear that all decisions on our professional requirements are entirely our responsibility. I am sure that all medically qualified preclinical teachers in Commonwealth universities will be following with great interest the achievements of the Medical Academic Staff Committee.

C W OGLE

Department of Pharmacology,

Faculty of Medicine

University of Hong Kong,

Hong Kong

1 British Medical fournal, 1979, 2, 146

Lewin, W, Fournal of the World Medical Association, 1978, 25, 76.

\section{Consensus management}

SIR,-Professor G P McNicol's comment on consensus management (6 October, p 844) prompts me to invite him to come to Dundee. We think that he will find an executive group which is neither mediocre, indecisive, lacking in imagination and drive, or prone to shillyshallying and procrastination.

We could not identify a prima donna in our mixed sex group, but what we do have is a sense of humour which enables us to take such generalisations in our stride.

G G SAVAGE

Secretary, Tayside Health Board

Dundee DD1 9NL

\section{Medical examination for elderly drivers}

SIR,-I would like to be enlightened about the present situation between the BMA and the motor insurance companies over this matter.

Some years ago I wrote to the BMA about this and received the reply that negotiations were difficult but in hand. Since then I notice an increasing number of the elderly, hesitantly proffering their report forms which all contain the sentence "any fee charged must be payable by the policy holder." Some companies, with crocodile tears, have inserted the word "unfortunately." Surely, this unsatisfactory, embarrassing, and sloppy state of affairs has gone on long enough.

I feel strongly that this examination should be paid for by the insurance company that requests the certificate, and I do not understand why this is not the norm. After all, these insurance companies have all had hundreds, if not thousands, of pounds in premiums from their senior citizen clients in 